\title{
THE EFFICIENCY OF HYALURONIC ACID IN THE MANAGEMENT OF RADIATION INDUCED CYSTITIS
}

\author{
RADU DRAGOS MARCU ${ }^{1,2}$, ARSENIE DAN SPINU ${ }^{1,2} *$, DAN LIVIU DOREL MISCHIANU ${ }^{1,2,3}$, \\ IOANA SORINA OPREA ${ }^{4}$, CAMELIA CRISTINA DIACONU ${ }^{2,5}$, BOGDAN SOCEA $^{2,6}$, OVIDIU \\ GABRIEL BRATU ${ }^{1,2,3}$
}

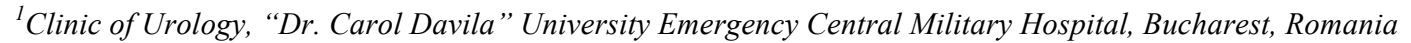 \\ 2 "Carol Davila" University of Medicine and Pharmacy, Bucharest, Romania \\ ${ }^{3}$ Academy of Romanian Scientists, Bucharest, Romania \\ ${ }^{4}$ Intensive Care Unit, "Dr. Carol Davila” University Emergency Central Military Hospital, Bucharest, Romania \\ ${ }^{5}$ Department of Internal Medicine, Emergency Clinical Hospital, Bucharest, Romania \\ ${ }^{6}$ Surgery Department, "Sf. Pantelimon” Emergency Hospital, Bucharest, Romania
}

*corresponding author:dan.spinu@yahoo.co.uk

\begin{abstract}
Radiation cystitis is a complex pathology, with a significant negative impact on the patient's quality of life, often proving to be a real challenge for physicians due to its bothersome symptoms and severe complications such as recurrent haematuria. The mechanism involved in radiation induced cystitis pathogenesis is the injury of the bladder's urothelium and its glycosaminoglycans layer. We have analysed the current data in terms of radiation induced cystitis and the role of the glycosaminoglycans replenishment therapy with hyaluronic acid in the management of radiation cystitis. The efficiency of hyaluronic acid in the management of radiation cystitis has been evaluated by a small number of clinical trials, but all of them have provided good results in terms of safety, as well as in improving the urinary symptoms and the patient's quality of life.
\end{abstract}

\section{Rezumat}

Cistita radică este o patologie complexă, cu un impact negativ semnificativ asupra calității vieții pacienților, din cauza simptomatologiei și a complicațiilor severe, cum ar fi hematuria, deseori tratamentul fiind o adevărată provocare pentru clinicieni. Mecanismul patogenic al cistitei radice este reprezentat de afectarea uroteliului vezical şi a stratului acestuia de glicozaminoglicani. Am analizat datele actuale din studiile clinice efectuate privind rolul refacerii glicozaminoglicanilor şi am concluzionat că eficiența acidului hialuronic în tratamentul cistitei radice este satisfăcătoare, ca și profil de siguranță, dar și din punct de vedere clinic, ameliorând simptomele urinare și îmbunătățind calitatea vieții bolnavilor.

Keywords: radiation cystitis, bladder, hyaluronic acid, haematuria

\section{Introduction}

Radiation cystitis following high dose pelvic radiotherapy for different types of malignancies (prostate cancer, rectal cancer, cervix cancer) is a severe complication that severely affects the patient's quality of life. Often this pathology and its management proves to be a real challenge for physicians due to its bothersome symptoms, especially in the cases with severe bleeding which can significantly increase the vital risk.

The risk of radiation cystitis depends on the radiotherapy technique as well as on the total radiation dose. It has been reported that a total dose of $65 \mathrm{~Gy}$ is the upper limit in order to obtain a low risk of genitourinary complications (less than $5 \%$ ), while a total dose of $80 \mathrm{~Gy}$ associates a risk of urinary complications that exceeds $50 \%[12,13]$. The development of new radiotherapy techniques has led to a decrease of the local radiation complications.
Therefore compared to conformal 3D radiotherapy the introduction of intensity modulated radiotherapy has allowed the restriction of the irradiated area, limiting the exposure of the normal and healthy surrounding tissues, as well as a decrease of complications rates, especially urinary complications. Even so, it has been reported that a total dose of radiation of over $70 \mathrm{~Gy}$ administered using the intensity modulated radiotherapy technique can associate low urinary tract symptoms in approximately half of the cases $[9,13,14]$.

According to literature the incidence of post-radiation cystitis can range between $20 \%$ and $80 \%$, this large variation depending on the radiotherapy technique and on the total dose of radiation [3, 19]. In terms of gender distribution it has been noticed that radiation induced cystitis is more frequently encountered in the male population, this being explained by the increasing number of male patients diagnosed with prostate cancer who undergo radiotherapy $[7,18,24]$. 
It is estimated that up to $25 \%$ of the male patients who undergo radiotherapy for prostate cancer will develop during radiotherapy or during the following weeks/months nocturia as well as other low urinary tract symptoms. The image guided intensity modulated radiotherapy significantly reduces the radiation bed, limiting the bladder exposure, but even so if high doses of radiation are applied this will unavoidable affect the bladder neck and the urethra leading to low urinary tract symptoms such as: dysuria, urinary frequency, urgency, nocturia, the sensation of incomplete bladder voiding, microscopic haematuria or macroscopic haematuria. The latter often leads to real problems in terms of its management, due to its associated complications such as blood clots formation which can lead to complete or incomplete urinary retention with ureterohydronephrosis that will affect the renal function resulting in acute renal failure or chronic kidney disease which will need dialysis [1, 4, 6, 26, 29].

It has been reported that radiotherapy related haematuria occurs in approximately $5 \%$ to $10 \%$ of the patients who undergone this form of treatment. The recurrence of haematuria frequently leads to the need of endoscopic procedures in order to remove the obstructive bladder blood clots and to ensure haemostasis. The endoscopic bladder exploration can reveal an oedematous, congestive, friable bladder mucosa with multiple teleangiectasias and diffuse bleeding which may prove difficult to control using the endoscopic approach, often being necessary other therapeutic options such as arterial embolization, or a more radical approach such as salvage cystectomy with urinary diversion. The ureteral orifices can be embedded in the oedematous process, this being another cause for ureterohydronephrosis and chronic kidney disease. Depending on the moment of their occurrence these radiation related reactions can be classified as acute (during radiotherapy), subacute (within the first weeks/months following radiotherapy) and late reactions (six months after radiotherapy). Nevertheless, low urinary tract symptoms and haematuria can occur even several years after radiotherapy, this being explained by the radiation induced bladder wall structural changes $[11,22$, $28]$. The acute and subacute reactions can affect $20 \%-80 \%$ of the patients who undergo radiotherapy for different pelvic malignancies. These reactions can be temporary, lasting for several weeks or months, or they can persist due to the irreversible fibrotic changes of the bladder walls which will lead to a small fibrotic, inextensible bladder and furthermore to the reduction of the bladder capacity (less than $150 \mathrm{~mL}$ ) and to low urinary tract symptoms [2, 20, 26, 29].

The diagnosis of radiotherapy induced cystitis implies the exclusion of other causes that can lead to urinary symptoms similar to those encountered in cystitis and is based on urinalysis, urine culture and cytology, patients history and physical examination, imaging exploration for those with persistent haematuria in order to exclude a potential malignant cause such as kidney tumours that invade the urinary tract or upper urinary tract neoplasia [3].

\section{Physiopathology}

The bladder's urothelium is coated by a layer of glycosaminoglycans that ensures the protection of the mucosa and of the underlying cells from the irritant action of the substances found in urine. The injury of the bladder's urothelium during radiotherapy seems to be the main mechanism involved in radiation cystitis pathogenesis. Radiation damages and disrupts the glycosaminoglycans layer exposing the underlying interstitial cells, smooth muscle cells, nerves and vasculature to urine and its toxic elements, leading to the inflammation of the sub-epithelial layer and to the activation of the $\mathrm{C}$-fibers. This has an irritating effect on the smooth muscle fibres and it explains the acute low urinary tract symptoms phase. The $\mathrm{C}$ fibres are unmyelinated peptide-containing fibres involved in the micturition reflex, as well as in the sensation of pain and in the visceral reflex, through their afferent functions. The $\mathrm{C}$-fibres also regulate the migration of the immune cells, the mast cells degranulation, the contraction of the smooth muscle fibres, neurogenic inflammation, neuromodulation and neuroplasticity, through their efferent function [16, 17]. The chronic exposure of the sub-urothelial cells and $\mathrm{C}$-fibres to urine irritants due to the persistent defect of the glycosaminoglycans layer will eventually lead to the alteration of the normal neuronal sensitivity and to an abnormal and exaggerated perception of the normal stimuli, these patients experiencing pain or abnormal discomfort in situations such as mild bladder inflammation or during the bladder filling process [16].

Exposure to radiation will result in urothelial cells nuclear irregularities, cellular oedema, disruption of the intercellular junctions, smooth muscle cell oedema, vascular endothelial cell oedema and ischemia, endothelial cell proliferation. As a result of the inflammatory and of the ischemic process structural changes will occur: collagen deposition, perivascular fibrosis and muscle cells replacement by fibroblasts, which will gradually and significantly alter the bladders capacity, resulting in voiding dysfunction [3, 20]. These structural changes can be seen more clearly after several months since the start of radiotherapy. The urothelium recovery process needs several further months after the cease of radiation, due to its slow turnover rate, but even so a full recovery is not guaranteed, due to the irreversible fibrotic changes that can occur at the level of the bladder walls [19]. 
FARMACIA, 2019, Vol. 67, 1

Hyaluronic acid (HA) and chondroitin sulphate (CS) are essential elements of the bladders glycosaminoglycans layer. These mucopolysaccharides have an important role in terms of protecting the urothelium from the action of various irritating agents found in urine that could significantly alter its integrity. HA is a major component of the extracellular matrix, being well represented in the connective, epithelial and neural tissues and has an important role in the cell proliferation and cell migration process. HA also seems to have an immune-modulatory effect due to the fact that it inhibits leukocyte migration and aggregation as well as the adherence of immune complexes to polymorphonuclear cells [16]. It also interferes with the endothelial cell proliferation as well as in the replacement of smooth muscle cells by fibroblasts, regulating these processes [21, 23, 26, 29]. Several studies have underlined the potential positive effects of glycosaminoglycans (GAG) replenishment treatment using HA with or without CS, reporting that CS may lead to the recovery of GAG layer and that HA could interfere with the inflammatory process, thus limiting the radiation induced cystitis symptoms and favouring a much faster recovery [13]. The efficiency of hyaluronic acid in interstitial cystitis has been demonstrated by numerous studies, but in terms of its efficiency in the management of radiation cystitis there is a lack of consistent data due to the reduced number of clinical trials.

\section{Clinical trials}

Vasssilis and his colleagues evaluated the potential positive effect of hyaluronic acid bladder instillations in patients with radiation cystitis secondary to radiotherapy for prostate cancer. 20 patients with radiation cystitis (grade II or III), have been enrolled in this study. The total radiation dose has ranged between 72 and $74 \mathrm{~Gy}$, with a median period of time since the end of radiotherapy to the onset of the symptoms of 9.5 months, ranging between 6 and 14 months. Before the initiation of the bladder instillation treatment with HA a cystoscopy was performed in every case. The therapeutic protocol consisted in a weekly bladder instillation of a $40 \mathrm{mg}$ HA dose for one month, followed by a monthly instillation during the next two months. Prior to the instillation the patient was urged to empty his bladder and afterwards to avoid urinating for at least an hour. At the end of the three months treatment a secondary cystoscopy was performed in order to assess the impact of the HA instillations on the bladder's urothelium. Before initiating the treatment it was noticed that approximately $70 \%$ of the patients have presented grade III cystitis, complaining of low urinary tract symptoms like nocturia, dysuria, important and recurrent haematuria, urinary frequency and other symptoms that were secondary to the reduction of the bladders capacity and compliance. During cystoscopy it was found that these patients presented a congestive bladder mucosa and numerous teleangiectasias. The remaining $30 \%$ of the patients presented stage II cystitis with moderate symptoms, intermittent haematuria and fewer teleangiectasias than those encountered in the grade III cystitis group. According to the authors the HA treatment has led to a significant improvement of the patients symptoms, as well as in terms of the cystoscopy findings. Therefore after the 3 months treatment it has been reported that $45 \%$ of the patients have presented grade I cystitis and 55\% grade II, without finding any grade III lesions during the endoscopic bladder examination. None of the patients have developed any secondary unwanted reactions during the treatment, this therapeutic option being well tolerated and with good results [29].

In a 2015 study Gacci has published the results of sodium hyaluronate and chondroitin sulphate bladder instillations in 23 patients with post-radiation cystitis. The median radiation dose received during therapy was $67.9 \pm 2$ Gy. All the patients included in this study have reported after radiotherapy at least stage II toxicity according to the Radiation Therapy Oncology Group (RTOG) classification. According to the authors the patients included in the study presented negative urine cultures and they did not have a recent history of bladder catheterization for acute urinary retention, nor urinary tract infections or urinary lithiasis. 18 patients out the total 23 have complained of nocturia. The patients have received a weekly bladder instillation with HA (HA $1.6 \% 800 \mathrm{mg} / 50 \mathrm{~mL})$ and CS $(2 \%$ $1000 \mathrm{mg} / 50 \mathrm{~mL}$ ) for one month, followed by other instillations on weeks 6,8 and 12. The patients have been evaluated using the International Cystitis Symptoms Index - question 3 and the International Cystitis Problem Index - question 2. At the end of treatment, during the periodic follow-ups it was found that the bladder instillation therapy has led to a significant improvement of the questionnaires as well as in terms of voiding dysfunction recovery and nocturia. Therefore $56 \%$ of the patients have reported improvements regarding the number of nocturnal voids, whereas $44 \%$ of the patients did not encountered any significant improvements and only one patient has reported more severe symptoms when compared to those that were present before the bladder instillation treatment. The authors have reported that the treatment has been well tolerated, without any major side effects [13].

In a non-randomized study Hazewinkel evaluated the prophylactic role of bladder instillations with $0.2 \%$ chondroitin sulphate $(\mathrm{CS})$ in terms of reducing the risk of radiation cystitis. 20 patients with gynaecological malignancies (cervical or endometrial neoplasia) for whom radiotherapy was indicated have been enrolled in this study. Only half of the patients have received a weekly $40 \mathrm{~mL} 0.2 \% \mathrm{CS}$ bladder 
instillation for a period of six weeks. The patients were evaluated using the visual analogue scale and the urogenital distress inventory. The authors have reported that in the CS group fewer bothersome over active bladder symptoms have been encountered, as well as fewer urinary incontinence and obstructive micturition symptoms. The CS instillations have been well tolerated, only one patient dropping out of this trial after 4 weeks due to urethral pain [15].

The role of hyperbaric oxygen (HBO) therapy in the management of radiation induced cystitis has been debated in numerous studies. In a randomized clinical trial Shao has compared the efficiency of this type of treatment with bladder HA instillations in patients with cystitis secondary to radiotherapy [26]. This study was based on 36 patients who have undergone radiotherapy for different pelvic malignancies. The authors have randomly divided the 36 patients into two subgroups: 16 patients who have received bladder instillation therapy and in 20 patients the HBO approach were used. The HA group of patients have received a dose of $40 \mathrm{mg} \mathrm{HA}$ that was instilled in the bladder once a week for a month and afterwards once a month for two months, whereas the HBO patients have received a daily $100 \%$ oxygen in a hyperbaric chamber for approximately 60 minutes at a pressure of $2.5 \mathrm{~atm}$. The HBO treatment was carried out over a median period of 30 days. The authors have stated that the symptoms, frequency of voiding and analogue visual scale of pelvic pain have been evaluated before initiating one of the two forms of treatment and at the end of the treatment. Afterwards the treatment efficiency was assessed every six months for 18 months and it was stated that complete remission was achieved when all the symptoms had disappeared. During the periodic follow-ups significant improvements have been found in both groups, without any major differences between the two types of treatment. The authors have reported that urinary frequency had significantly decreased in both groups at the 6 months evaluation, this improvement persisting until the 12 months examination in the HA group, but not in the HBO group. The improvements of the visual analogue scale of pelvic pain remained significant in both groups at the 18 months follow-up. No major side-effects have been encountered during the HA therapy, in one case further bladder instillations with HA being necessary after the recurrence of macroscopic haematuria (at 15 months). The HA group presented a higher risk of urinary tract infection when compared to the HBO group, this being related to the urethra-vesical catheterization during bladder instillations (approx. $43 \%$ for the HA group compared to $10 \%$ in the HBO group - in the first six months) [26].

A prospective study conducted on 69 male patients with radiation and chemical cystitis has evaluated the efficiency of sodium hyaluronate. 15 patients have presented symptoms following radiotherapy for prostate cancer and 54 patients have complained of low urinary tract symptoms after bladder instillations for nonmuscle invasive bladder cancer (24 patients have received instillations with $\mathrm{BCG}$ and in 30 cases Mytomicin $\mathrm{C}$ instillation was the drug of choice). After establishing the diagnostic of radiation or chemical induced cystitis, all of the 69 patients have undergone a therapeutic protocol that consisted in a weekly bladder instillation with $40 \mathrm{mg}$ sodium hyaluronate for 8 to 24 months, depending on the symptoms remission. The authors have reported that even if symptoms complete remission had been obtained within the first month of the treatment, the bladder instillations would have been performed for at least another four weeks, due to the high risk of recurrence. During the first month instillations the patients have also received $32 \mathrm{mg}$ dexamethasone, due to its topical anti-inflammatory effect. The treatment resulted in a significant improvement of the patient's quality of life this being related to the partial or complete remission of the lower urinary tract symptoms and due to the enlargement of the bladders capacity, which has led to a reduction of the urinary frequency. At the end of the treatment the authors have reported that in the prostate cancer group the bladders capacity had increased to $243.3 \mathrm{~mL}$ from $85 \mathrm{~mL}$, this raise being slightly higher in the bladder cancer group. Cystitis associated pelvic pain was evaluated using the visual analogue scale. The first results of the sodium hyaluronate treatment could have been seen after only four bladder instillations. In terms of pain relief it was noticed that this therapeutic approach has led to a significant decrease of the visual analogue scale scores $(0.9$ after the treatment versus 8.6 prior to the bladder instillations). It was concluded that $97 \%$ of the patients have achieved complete symptoms relief and that the response in the chemical induced cystitis group was slightly superior when compared to the radiotherapy group [27].

Bladder instillations with hyaluronic acid prior to brachytherapy have proven to reduce the incidence of radiation bladder toxicity as shown in the study conducted by Samper Ots and his colleagues [25]. The authors have reported a significant lower incidence of radiation induced cystitis symptoms in the group of patients who have received HA compared to those without HA, the first results being noted after the first two sessions $(20.8 \%$ compared to $40.4 \%)$. The rate of grade $\geq 2$ cystitis encountered during the study in the HA group was $2.08 \%$, whereas in the non-HA group this percentage was significantly higher (12.8\%) [25].

The hyaluronic acid treatment in the management of radiation induced cystitis is not yet used on a large scale, this being related in general to the low number of clinical trials that have assessed its effects. Despite this reason, the previously presented trials 
have obtained good results, all of them concluding that HA bladder instillations have decreased the rate of low urinary tract symptoms and it has significantly improved the patient's quality of life.

The urothelial GAG layer replenishing therapy using HA and/or CS has proved to be successful in interstitial cystitis. Numerous clinical trial have confirmed its positive effects in terms of low urinary tract symptoms and quality of life improvements, making of it a mainstream treatment for this pathology. If we take into account that both interstitial cystitis and radiation induced cystitis have a defect at the level of the urothelial GAGs layer and the fact that the treatment with hyaluronic acid has proven to be a successful choice of treatment in interstitial cystitis, then more physicians should use HA in the management of radiation induced cystitis.

The HA bladder instillations have also proven be to efficient in terms of reducing the rate of urinary tract infections recurrence, as well as improving the urinary symptoms, the patients quality of life and ensuring a greater period of time until the recurrence of the infection $[8,10]$. A 2014 study has evaluated the potential use of HA and CS bladder instillations as a treatment alternative to antibiotics in order to ensure the prophylaxis of recurrent urinary infections. The authors have published encouraging results and they have concluded that restoring the integrity of the GAG barrier with the help of HA and CS could significantly reduce the incidence of infection recurrence and that this option can be a feasible alternative to the antibiotic prophylaxis [5].

\section{Conclusions}

Radiation cystitis is a complex pathology that severely affects the patient's quality of life, often proving to be a real challenge for physicians due to its bothersome symptoms and severe complications, such as severe bleeding. The injury of the bladder urothelium and its glycosaminoglycans layer during radiotherapy seems to be the main mechanism involved in the pathogenesis of radiation cystitis. The efficiency of hyaluronic acid in the management of interstitial cystitis has been demonstrated by numerous studies, but in terms of its efficiency in the management of radiation cystitis there is a lack of consistent data due to the reduced number of clinical trials. Nevertheless the existing clinical trials have provided good results, therefore demonstrating that bladder instillations with HA can be a safe and efficient therapeutic option for the management of radiation induced cystitis.

\section{Conflicts of interest}

All authors declare that there are no conflicts of interest.

\section{Acknowledgement}

This paper is supported by project "Eficiența tratamentului $\mathrm{cu}$ acid hialuronic $\hat{\imath} n$ cistita radică" (The Efficiency of treatment with hyaluronic acid in radiation induced cystitis), Contract no. 10/02.05.2018, project on-going with the Academy of Romanian Scientists.

\section{References}

1. Anghelache L, Marinescu B, Isvoranu G, Cringanu D, Niculae A, Bratu O, Cytostatic therapy on tumor bearing mice: biochemical and hematological aspects. Modern Medicine, 2016; 23(1): 26-32.

2. Berveling MJ, Langendijk JA, Beukema JC, Mourits MJ, Reyners AK, Pras E, Health-related quality of life and late morbidity in concurrent chemoradiation and radiotherapy alone in patients with locally advanced cervical carcinoma. J Gynecol Oncol., 2011; 22(3): 152-160.

3. Browne C, Davis NF, Mac Craith E, Lennon GM, Mulvin DW, Quinlan DM, Vey GP, Galvin DJ, A narrative review on the pathophysiology and management for radiation cystitis. Advances in Urology, 2015; 2015: 1-7.

4. Bulai C, Geavlete P, Ene C, Bratu O, Peride I, Niculae A, Geavlete B, A long term clinical comparison in cases of high volume benign prostatic obstruction-bipolar plasma enucleation versus standard prostatectomy. Modern Medicine, 2016; 23(3): 201-209.

5. Cicione A, Cantiello F, Ucciero G, Salonia A, Torella M, De Sio M, Autorino R, Carbone A, Romancik M, Tomaskin R, Damiano R, Intravesical treatment with highly-concentrated hyaluronic acid and chondroitin sulphate in patients with recurrent urinary tract infections: results from a multicentre survey. Can Urol Assoc J., 2014; 8(9-10): 721-727.

6. Cozma CN, Raducu L, Avino A, Scaunasu RV, Bratu O, Marcu DR, Jecan CR, A rare case of vulvar squamos cell carcinoma; case presentation. J Clin Investig Surg., 2018; 3(1): 32-36.

7. Crew JP, Jephcott CR, Reynard JM, Radiation-induced haemorrhagic cystitis. European Urology, 2001; 40(2): 111-123.

8. Damiano R, Quarto G, Bava I, Ucciero G, de Domenico R, Palumbo MI, Autorino R, Prevention of recurrent urinary tract infections by intravesical administration of hyaluronic acid and chondroitin sulphate: a placebocontrolled randomised trial. Eur Urol, 2011; 59(4): 645-651.

9. de Langhe S, de Ruyck K, Ost P, Fonteyne V, Werbrouck J, de Meerleer G, de Neve W, Thierens H, Acute radiation-induced nocturia in prostate cancer patients is associated with pretreatment symptoms, radical prostatectomy, and genetic markers in the TGFb1 gene. Int J Radiat Oncol Biol Phys., 2013; 85(2): 393-399.

10. de Vita D, Giordano S, Coppola E, Prospective observational study of intravesical sodium hyaluronate and chondroitin sulfate in women with chronic cystitis, recurrent bacterial cystitis: preliminary data. $86^{\text {th }}$ SIGO Congress, 14 - 17 November 2010, Milan, Italy. 
11. Diaconu C, Iancu M, Dediu G, Bălăceanu A, Paraschiv B, Bratu O, Enache V, Strange relationship between cancer and hemophilia. Archives of the Balkan Medical Union, 2017, 52(2): 201-205.

12. Emami B, Lyman J, Brown A, Coia L, Goitein M, Munzenrider JE, Shank B, Solin LJ, Wesson M, Tolerance of normal tissue to therapeutic irradiation. Int J Radiat Oncol Biol Phys., 1991; 21(1): 109-122.

13. Gacci M, Saleh O, Giannessi C, Detti B, Livi L, Monteleone Pasquetti E, Masoni T, Finazzi Agro E, Li Marzi V, Minervini A, Carini M, Gravas S, Oelke $\mathrm{M}$, Serni S, Sodium hyaluronate and chondroitin sulfate replenishment therapy can improve nocturia in men with post-radiation cystitis: results of a prospective pilot study. BMC Urology, 2015; 15: 1-6.

14. G de Meerleer, L Vakaet, S Meersschout, G Villeirs, A Verbaeys, W Oosterlinck, W de Neve, Intensitymodulated radiotherapy as primary treatment for prostate cancer: acute toxicity in 114 patients. Int $J$ Radiat Oncol Biol Phys., 2004, 60(3): 777-787.

15. Hazewinkel MH, Stalpers LJ, Dijkgraaf MG, Roovers JP, Prophylactic vesical instillations with $0.2 \%$ chondroitin sulfate may reduce symptoms of acute radiation cystitis in patients undergoing radiotherapy for gynecological malignancies. Int Urogynecol J., 2011; 22(6): 725-730.

16. Lazzeri M, Hurle R, Casale P, Buffi N, Lughezzani G, Fiorini G, Peschechera R, Pasini L, Zandegiacomo S, Benetti A, Taverna G, Guazzoni G, Barbagli G, Managing chronic bladder diseases with the administration of exogenous glycosaminoglycans: An update on the evidence. Therapeutic Advances in Urology, 2016; 8(2): 91-99.

17. Lazzeri M, Editorial comment on: a refocus on the bladder as the originator of storage lower urinary tract symptoms: a systematic review of the latest literature. Eur Urol., 2009; 56(5): 820.

18. Levenback C, Eifel PJ, Burke TW, Morris M, Gershenson DM, Hemorrhagic cystitis following radiotherapy for stage $\mathrm{Ib}$ cancer of the cervix. Gynecologic Oncology, 1994; 55(2): 206-210

19. Marks LB, Carroll PR, Dugan TC, Anscher MS, The response of the urinary bladder, urethra, and ureter to radiation and chemotherapy. Int $\mathrm{J}$ Rad Oncol Biol Physics, 1995; 31(5): 1257-1280

20. McDonnell BM, Buchanan PJ, Prise KM, McCloskey $\mathrm{KD}$, Acute radiation impacts contractility of guineapig bladder strips affecting mucosal-detrusor interactions. PLoS ONE, 2018; 13(3): 1-15.

21. Miodosky M, Abdul-Hai A, Tsirigotis P, Or R, Bitan M, Resnick IB, Gesundheit B, Zilberman I, Ioffe L, Leubovic A, Slavin S, Shapira MY, Treatment of post-hematopoietic stem cell transplantation hemorrhagic cystitis with intravesicular sodium hyaluronate. Bone Marrow Transplant, 2006; 38(7): 507-511.

22. Paraschiv B, Dediu G, Iancu A, Bratu O, Diaconu C, Superior vena cava syndrome. Archives of the Balkan Medical Union, 2017; 52(1): 39-43.

23. Parsons CL, The therapeutic role of sulfated polysaccharides in urinary bladder. Urol Clin North Am., 1994; 21(1): 93-100.

24. Pavlidakey PG, MacLennan GT, Radiation cystitis. Journal of Urology, 2009; 182(3): 1172-1173.

25. Samper Ots PM, Lopez Carrizosa C, Rodríguez A, de Dios Sáez J, Delgado JM, de Miguel M, Vidal M, Vesical instillations of hyaluronic acid to reduce the acute vesical toxicity caused by high - dose brachytherapy do not affect the survival: a five-year followup study. Clin Transl Oncol., 2009; 11(12): 828-834

26. Shao Y, Lu GL, Shen ZJ, Comparison of intravesical hyaluronic acid instillation and hyperbaric oxygen in the treatment of radiation-induced hemorrhagic cystitis. BJU International, 2011; 109(5): 691-694.

27. Sommariva ML, Sandri SD, Ceriani V, Efficacy of sodium hyaluronate in the management of chemical and radiation cystitis. Minerva Urol Nefrol., 2010; 62(2): 145-150.

28. Supriya M, Madan R, Julka PK, Rath GK, Radiation induced cystitis and proctitis - prediction, assessment and management. As Pac J Cancer Prevent., 2015, 16(14): 5589-5594.

29. Vasssilis K, Eftychia M, Andreas F, Ivelina B, Charalampos A, Use of hyaluronic acid (Cystistat) for the treatment of late radiation induced cystitis in patients after prostate irradiation. $J$ Bioequiv Availab., 2014; 6: 18-22. 